\title{
SEROPREVALENCE OF BRUCELLOSIS IN SHEEP IN THE GAIBANDHA DISTRICT OF BANGLADESH
}

\author{
M. S. Rahman*, M. N. Rahaman, M. T. Islam, R. R. Sarker, M. A. S. Sarker, \\ M. Sarabontuhura, A. Chakrabartty, L. Akther ${ }^{1}$ and M. J. Uddin \\ Department of Medicine, Bangladesh Agricultural University \\ Mymensingh-2202, Bangladesh
}

\begin{abstract}
Brucellosis is an important zoonoses causing signififant economic loss but is very often neglected in Bangladesh. Therefore, a survey was undertaken to investigate the seroprevalence of brucellosis in sheep of selected areas (Gaibandha sadar and Gobindagonj upazilas) in the Gaibandha districts of Bangladesh. A total of 206 sera samples were collected from sheep and were tested for presence of Brucella specific antibody by Rose Bengal Plate Test (RBPT) as screening test and the RBPT positive samples were further confirmed using indirect Enzyme-linked immunosorbent assay (i-ELISA). Information of sheep's age, sex, housing system, pregnancy status, abortion and reproductive disorder were collected using questionnaire. The overall seroprevalence of brucellosis in sheep was recorded as 3.39\% in RBPT and $2.91 \%$ in i-ELISA. The prevalence of brucellosis in female sheep $(3.41 \%)$ was higher than male $(3.33 \%)$. The prevalence of brucellosis in sheep with abortion history was higher $(4.34 \%)$ than the sheep with no abortion (3.08\%). The highest prevalence of brucellosis $(4.00 \%)$ was found in sheep keeping with others species such as cattle and goat compared to the sheep keeping alone $(1.79 \%)$. The higher rate $(4.59 \%)$ of Brucella antibody was recorded in sheep of 1-2 years of age. Brucellosis might be an important hinders for sheep production in Bangladesh. The present study will help to develop an appropriate prevention strategy for brucellosis in Bangladesh.
\end{abstract}

Key Words: Seroprevalence, Brucellosis, Sheep, RBT, I-ELISA

\section{INTRODUCTION}

Brucellosis is a major constraint for the development of livestock in Bangladesh. Brucellosis was first detected in cattle (Mia and Islam, 1967), in buffalo (Rahman et al., 1997) and in human (Rahman et al., 1983). It is widely studied in cattle (Rahman et al., 2009, 2006; Amin et al., 2004) but limited information could be found in the case of small ruminants such as sheep and goats. However, sheep and goats are playing an important role in the economic well being of the resource-poor farmer. The epidemiology of

1 Department of Livestock Services, Krishi Khamar Sarak, Farmgate, Dhaka-1215, Bangladesh

*Correspondence Address:- E-mail: prithul02@yahoo.co.uk, Tel: 008809152184 
Brucella sp. is believed to be complex and it is influenced by several non-technical and technical phenomena. The density of animal populations, the herd size, the type and breed of animal (dairy or beef), the type of husbandry system and other environmental factors are thought to be important determinants of the infection dynamics (Uddin et al., $2007 a, b)$. Brucellosis remains a major source of disease in humans and domesticated animals worldwide. Although the prevalence of this disease varies widely from country to country, small ruminant brucellosis is mostly caused by B. meltensis. (Redkar et al., 2001). B. ovis is also an important cause of orchitis and epididymitis in sheep but it is not recognized as a cause of natural infection in goats. Brucellosis spreads between animals in a herd and the disease is a systemic infection that can involve many organs and tissues. Once the acute period of the disease is over, symptoms of brucellosis are mostly not pathognomonic, and the organism can be chronically located in the supramammary lymphatic nodes and mammary glands of $80 \%$ of infected animals. Thus they continue to secrete the Brucella organism in their body fluids (Redkar et al., 2001).

The brucellosis can have a considerable impact on human and animal health, as well as socioeconomic impacts, especially in which income relies largely on livestock breeding and dairy products. Brucellosis in human beings is caused by exposure to livestock and livestock products. Infection can result from direct contact with infected animals and can also be transmitted to consumers through raw milk and milk products. Brucellosis has been reported in small ruminants from different parts of the world (Uddin et al., 2007b; Bandeg et al., 1989; Abd-el-Ghani et al., 1983). Brucellosis in cattle, buffalo and human beings has been widely investigated by many investigators (Rahman et al., 2006, 1983) but limited research has been done to unravel the seroprevalence of brucellosis in sheep. No study was carried out for brucellosis in Gaibandha in Bangladesh. Therefore, the aim of this study was carried to determine the seroprevalence of brucellosis in sheep in Gaibandha district of Bangladesh.

\section{MATERIALS AND METHODS}

\section{Experimental design}

Venous blood samples were collected aseptically from randomly selected 206 sheep in Gaibandha sadar and Gobindhagonj upazilas of Gaibandha districts of Bangladesh. During sampling, information on age, sex, breed, pregnancy status, reproductive problems such as repeat breeding, previous abortion and retention of placenta were recorded using questionnaire. After collection of data, about 5-7 ml of blood was collected aseptically from each of the randomly selected Black Bengal goats. All the blood samples were processed for sera preparation.

\section{Serological tests}

Rose Bengal plate test (RBPT) test were used for the diagnosis of brucellosis as screening test and the animals found positive in RBPT were further confirmed by i-ELISA test. 


\section{Rose bengal plate test (RBPT)}

The RBPT was performed according to the procedure as described by OIE (2004) and Uddin et al. (2007a,b). The test serum samples and Brucella antigen (William James House, Cowley Rd. Cambridge, CB4 0WX, UK) were kept one hour in room temperature before beginning of the test. A total of $30 \mu \ell$ of each serum to be tested was placed on a glass plate circled, approximately $2 \mathrm{~cm}$ in diameter. Then the vial of antigen was shacked gently and $30 \mu \ell$ of antigen was put beside each of the sera. The antigens and the serum were mixed on the plate with a stirrer and spread over the entire area enclosed by the circle. Then the plate was placed on a mechanical rotator as $80-100 \mathrm{rpm}$ for 4 minutes and the reading was taken immediately. Any agglutination or precipitation was considered as positive, whereas no reaction (negative) was indicated as the absence of Brucella antigen in the sera. The positive and negative reactions are given in Fig. 1.

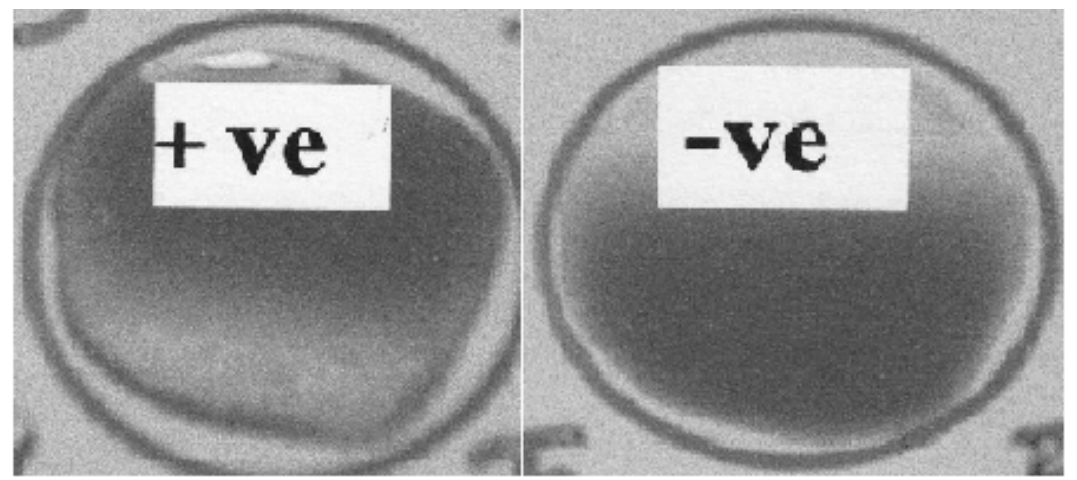

Fig. 1. Positive (+ve) and negative reaction of RBPT

\section{Indirect enzyme linked Immunosorbent assay (i-ELISA)}

The assay was performed according to the manufacturer's instructions (Svanova Biotech AB, art.No.10-2700-10, SE-751 83Uppasala, Sweden). First of all, the PBS-Tween Buffer and conjugate lyophilized horse radish peroxides (HRPO) conjugate was reconstituted immediately before use to perform i-ELISA. In brief, all reagent supplied by manufacturer was equilibrated to room temperature at 18 to $25^{\circ} \mathrm{C}$ before use. A volume of $100 \mu \ell$ of sample dilution buffer was added to each well by multichannel micropipette that would be used for serum samples and serum controls. After that $4 \mu \ell$ of positive control serum (Reagent A) and $4 \mu \ell$ of negative control serum (Reagent B) were added respectively, to selected wells coated with $B$. melitensis antigen. For conformation purposes, the experiment was run with the control sera in duplicates. A volume of $4 \mu \ell$ of sera samples were added to the selected well coated with B. melitensis antigen. For conformation purposes, the samples were also run in duplicates. The plate was shacked thoroughly and sealed the plate/strip and incubated at $37^{\circ}$ for one hour. The plates ware rinsed three times with PBST buffer and filled in the wells at each rinse, emptied the plate and tapped hard to remove all remains of fluid. Then $100 \mu \ell$ of HRP conjugate was added to each well 
and incubated at $37^{\circ}$ for one hour followed by a rinsing of the plate. Then $100 \mu \ell$ substrate solutions was added to each well and incubated for 10 minutes at room temperature. The reaction was stopped by adding $50 \mu \ell$ of stop solution to each well and mixed thoroughly. The stop solution was added in the same ordered as the substrate solution was added. The optical density (OD) of the controls and samples was measured at $450 \mathrm{~nm}$ in a microplate photometer. The OD was measured within 15 minutes after the addition of stop solution to prevent fluctuation in OD values. The positive and negative reactions are given in Fig. 2. The percent positivity values (PP) were calculated using the formula according to the manufacturer's guideline:

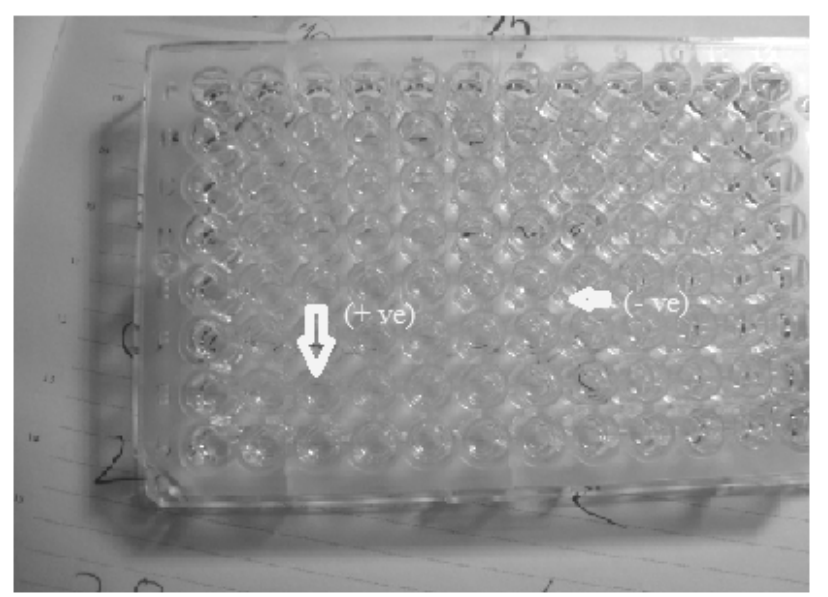

Fig. 2. Positive (+ve) and negative reaction of i-ELISA

\section{Statistical analysis}

The Chi-square test was employed to find out the significant relationship between the prevalence of brucellosis demographic variables (age, sex, species, breed etc) by using SPSS version 17.0.

\section{RESULTS}

Out of 206 samples, 56 and 150 samples were collected from Gaibandha sadar and Gobindhagonj upazilla of Gaibandha district, respectively. The overall prevalence of brucellosis in sheep was 3.39\% (Table 1). Sex wise seroprevalence of brucellosis revealed that prevalence in male was $3.33 \%$, whereas in case of female it was recorded as $3.41 \%$ which implies that prevalence of brucellosis in female sheep was higher than male sheep. However, the occurrence of brucellosis had no significant relationship with sex of sheep (Table 1). When age-wise seroprevalence of brucellosis was calculated, it was found that prevalence was lowest in sheep of 6 months to 1 years of age $(2.13 \%)$. The seroprevalence of brucellosis was recorded in sheep relatively higher (4.59\%) in 1 year to 2 years age group, compared to 2 years to 3 years age group (2.86\%), and no positive case was found on the age group above 3 years. 
Table 1. Seroprevalence of brucellosis and its association with different factors in sheep of Gaibandha district in Bangladesh

\begin{tabular}{|c|c|c|c|c|c|}
\hline & \begin{tabular}{|c|}
$\begin{array}{c}\text { Number of } \\
\text { sera samples } \\
\text { tested }\end{array}$ \\
\end{tabular} & \begin{tabular}{|c|} 
Number of \\
positive samples \\
in RBPT
\end{tabular} & \begin{tabular}{|c|} 
Number of \\
positive samples \\
in i-ELISA \\
\end{tabular} & $\begin{array}{c}\text { Prevalence } \\
(\%)\end{array}$ & $\begin{array}{c}\text { Level of } \\
\text { significance }\end{array}$ \\
\hline \multicolumn{6}{|l|}{$\overline{\text { Sex }}$} \\
\hline Male & 30 & 1 & 1 & 3.33 & \multirow{3}{*}{ NS } \\
\hline Female & 176 & 6 & 5 & 3.41 & \\
\hline Total & 206 & 7 & 6 & 3.39 & \\
\hline \multicolumn{6}{|l|}{ Age of animals } \\
\hline 6 months to 1 year & 47 & 1 & 1 & 2.13 & \multirow{4}{*}{ * } \\
\hline 1 year to 2 years & 109 & 4 & 4 & 4.59 & \\
\hline 2 year to 3 years & 35 & 1 & 1 & 2.86 & \\
\hline Above 3 years & 15 & 0 & 0 & 0 & \\
\hline \multicolumn{6}{|l|}{ Pregnancy status } \\
\hline Pregnant & 50 & 1 & 1 & 2 & \multirow[t]{2}{*}{ NS } \\
\hline Non-pregnant & 126 & 5 & 4 & 3.97 & \\
\hline \multicolumn{6}{|l|}{$\begin{array}{l}\text { Types of reproductive } \\
\text { disorders }\end{array}$} \\
\hline Anestrous & 44 & 1 & 1 & 2.27 & \multirow{6}{*}{ NS } \\
\hline Failure of conception & 52 & 3 & 2 & 5.77 & \\
\hline Retention of placenta & 32 & 1 & 1 & 3.12 & \\
\hline Dystocia & 5 & 0 & 0 & 0 & \\
\hline Repeat breeder & 27 & 1 & 1 & 3.70 & \\
\hline $\begin{array}{l}\text { Others (such as whitish } \\
\text { discharge) }\end{array}$ & 16 & 0 & 0 & 0 & \\
\hline \multicolumn{6}{|l|}{ Abortion history } \\
\hline Abortion & 46 & 2 & 2 & 4.34 & \multirow{2}{*}{ NS } \\
\hline No abortion & 130 & 4 & 3 & 3.08 & \\
\hline \multicolumn{6}{|l|}{ Keeping system } \\
\hline Keeping separately & 56 & 1 & 1 & 1.79 & \multirow[b]{2}{*}{ * } \\
\hline $\begin{array}{l}\text { Keeping with others } \\
\text { species }\end{array}$ & 150 & 6 & 5 & 4.00 & \\
\hline \multicolumn{6}{|l|}{ Floor type } \\
\hline Concrete floor & 41 & 1 & 1 & 2.43 & \multirow{2}{*}{ NS } \\
\hline Earthen floor & 165 & 6 & 5 & 3.64 & \\
\hline
\end{tabular}

NS = Not significant, ${ }^{*}$ Significant at $5 \%$ level of probability

Statistically, there is existed a significant $(\mathrm{P}<0.05)$ relationship between age of sheep and the prevalence of brucellosis (Table 1). Although, the prevalence of brucellosis had no significant relationship with reproductive problems of sheep statistically, there was variation for prevalence between sheep with different reproductive problem could be found (Table 1). Prevalence of brucellosis in sheep with history of anestrous $(2.27 \%)$, 
failure of conception $(5.77 \%)$, retention of placenta $(3.12 \%)$ and repeat breeder $(3.7 \%)$ are detected. The prevalence was higher in sheep with history of abortion $(4.34 \%)$ compared to the sheep with no abortion history (3.08\%). Keeping system of animals means whether the sheep kept separately or kept with other species such as cattle and goat have significant effect on the prevalence of brucellosis in sheep $(\mathrm{P}<0.05)$. The sheep kept separately had lower prevalence (1.79\%) compared to the sheep kept with other livestock $(4.0 \%)$ (Table1). Higher prevalence could be found in the sheep kept in the house with earthen floor $(3.64 \%)$ compared to the sheep kept in house with concrete floor $(2.43 \%)$ (Table 1).

\section{DISCUSSION}

Brucellosis remains as a major zoonosis worldwide (WHO, 1986). Although many countries have eradicated B. abortus from cattle, in some areas it has emerged as a cause of infection in this species as well as in sheep and goats. The importance of brucellosis was primarily due to its public health significance and economic loss to the animal industry (WHO, 1971). Bangladesh has been reported as an endemic country for brucellosis because of a considerable number of human and animal populations are exposed to the infection each year (Rahman et al., 2006). Definitive diagnosis of brucellosis can be accomplished only through the direct demonstration and identification of the causative agent(s) by culture and isolation procedures (Orduña et al., 2000).

The present investigation revealed that the overall seroprevalence of brucellosis in sheep was $3.39 \%$ which is higher than the overall seroprevalence of brucellosis, $2 \%$ reported by Amin et al. (2004). However, these results are close to the result of Abd-el-Ghani et al. (1983) reported 2.97\% brucellosis in sheep. This finding is in agreement with Rahman et al. (2006) who reported animal/individual-level seroprevalence of brucellosis in cattle is $2.4 \%-18: 4 \%$ while the herd-level seroprevalence in cattle is $62.5 \%$. It is difficult to compare these results with other in Bangladesh because there are limited studies on brucellosis in sheep. Osman and Adlan (1987) reported 0.27\% brucellosis of sheep in Saudi Arabia. Bandeg et al. (1989) reported brucellosis infection 3.2\% in Merino sheep in Kashmi. Burriel et al. (2002) found $16.8 \%$ of sheep were positive to Brucella infection in Greece. Prevalence rate of $1.7 \%$ in sheep and $1.5 \%$ in goats in Sudan (Abdalla, 1966); $6.01 \%$ in sheep and goats in Kenya (Waghela, 1976); 3.8\% in goats and 1.4\% in sheep in Eritrea (Omer et al., 2000); 4\% in goats and 1\% in sheep in eastern Sudan (El-Ansary et al., 2001). From 255 sheep and 289 goats slaughtered at an abattoir of New Delhi India, brucellosis was diagnosed in $9.02 \%, 4.31 \%, 27.45 \%$ and $10.95 \%$ sheep and $1.73 \%, 1.38 \%, 7.27 \%$ and $18.34 \%$ goats using RBPT, Standard Tube Agglutination Test (STAT), Complement Fixation Test (CFT) and dot - ELISA, respectively.

In case of age related seroprevalence in Gaibandha district, among the four age groups, the highest prevalence of brucellosis (4.59\%) was found in 1 to 2 years of age group. Sergeant (1994) found that there was no apparent association between age and serological status, or age and the prevalence. But Ghani et al. (1998) stated that several 
epidemiological factors, such as age, sex, breed, lactation number, herd size and living conditions influence the sero-prevalence of bruccllosis which is in agreement with our findings. It might explain because within this period at 1 to 2 years of age, the sheep is very active in reproduction. The prevalence of brucellosis in sheep was found to be higher $(3.41 \%)$ in female than male $(3.33 \%)$ which is similar to the findings recorded by Sharma et al. (2003). The prevalence of brucellosis was higher in sheep with abortion $(4.34 \%)$ as compared to non aborted sheep. Mahajan and Kulshreshtha (1987) found 56 positive cases out of 75 aborted sheep and 76 positive cases out of 373 healthy sheep. It could be explained because Brucella is one of the main bacterial causal agent causing abortion in sheep. In this study, higher prevalence of brucellosis was found in sheep keeping with cattle, buffalo and goat $(4.00 \%)$ as compared to separate keeping system $(1.79 \%)$. Omer et al. (2000) found $8.2 \%$ prevalence in individually reared sheep and $35.9 \%$ in herd sheep. The prevalence was higher in sheep housed on earthen floor $(3.64 \%)$ compared to the sheep housed on concrete floor $(2.43 \%)$. The earthen floor might be more suitable for the habitation and growing of bacteria and other microorganism compared to the concrete floor because the earthen floor is mostly damp and dirtier. Notably, it could be seen there are some discrepancies between the RBPT and i-ELISA in this study which is common in case of serological test because different serological tests such as RBPT, CFT, STAT and i-ELISA varies in sensitivity and specificity (Rahman et al., 2010 ).

\section{REFERENCES}

Abdalla, A. E. D. 1966. Sudan Veterinary Science. Anim. Health Husbandry, 7: 28.

Abd-el-Ghani, M., Osman, K. and Nada, S. M. 1983. Evaluation of serodiagnostic methods for brucellosis among sheep and goats in Egypt. Int. J. Zoonoses, 10(2): 132-137.

Amin, K. M. R., Rahman, M. B., Sarkar, S. K., Kabir, S. M. L. and Akand, M. S. I. 2004. Serological epidemiology of brucellosis in cattle of the Mymensingh district of Bangladesh. J. Anim. Vet. Adv., 3: 898-900.

Bandeg, S. D., Parvez, S. and Bandey, S. 1989. Seroepidemiological studies on brucellosis in exotic sheep in Kashmir Valley. Indian J. Anim. Sci., 59: 213-215.

Burriel, A. R., Vougiouka, O. M., Butsini, S., Nomikou, K. and Patakakis, M. 2002. A serologic investigation of some causes of reproductive failure among small ruminants in Greece. J. Vet. Res., 6: 57-63.

El-Ansary, E. H., Mohammed, B. A., Hamad, A. R. and Karom, A. G. 2001. Brucellosis among animals and human contacts in eastern Sudan. Saudi. Med. J., 22(2): 557-579.

Falade, S. and Hussein, A. H. 1997. Brucella sero-activity in Somali goats. Trop. Anim. Health Prod., 17: 93-99

Ghani, M., Zeb, A. and Siraj, M. 1998. Sero-incidence of bovine brucellosis in Peshawar district of Pakistan . Indian J. Anim. Sci., 68: 457.

Mahajan, N. K. and Kulshreshtha, R. C. 1987. Prevalence of brucellosis due to rough forms of Brucella in sheep. Indian J. Anim. Sci., 57: 1287-1289.

Mia, A. S. and Islam, H. 1967. A preliminary study on the incidence of bovine infertility and economic loss caused by it. Pakistan Vet. J., 1: 12-15.

Mudit, C., Singh, B. R., Hari, S., Meenu, A., Gautom, S., Agrawal, R. K. and Babu, N. 2005. Seroprevalence of brucellosis in chevon goats from Bareilly slaughterhouse. Indian J. Anim. Sci., 75: 220-221. 
Omer, M. K., Skjerve, E., Holstad, G., Woldehiwet, Z. and Macmillan, A. P. 2000. Prevalence of antibodies to Brucella spp. In cattle, sheep, goats, horses and camels in the state of Eritrea; influence of husbandry systems. Epidemiol. Infect., 125(2): 447-453.

Orduña, A., Almaraz, A., Pardo, A., Gutierrez, M. P., Garcia-Pascual, A., Dueñas, A., Cuervo, M., Abad, R., Hernández, B., Lorenzo, B., Bratos, M. A. and Torres, A. R. 2000. Evaluation of an immunocapture agglutination test (Brucellacapt) for serodiagnosis of human brucellosis. J. Clin. Microbiol., 38: 4000-4005.

Osman, A. M. and Adlan, A. M. 1987. Sudan. Brucellosis in domestic animals. prevalence diagnosis and control. Technical Series O. I. E., 6: 65-70.

Rahman, M. A., Islam, M. S., Alam, M. G. S. and Shamsuddin, M. 1997. Seroprevalence of brucellosis in the buffalo (Bubalus bubalis) of a selected area in Bangladesh. Buffalo J., 2: 209-214.

Rahman, M. M., Choudhury, T. I. M. F. R., Rahman, A. and Haque, F. 1983. Seroprevalence of human and animal brucellosis in Bangladesh. Indian Vet. J., 60: 165.

Rahman, M. S., Alam, N., Rahman, A. K. M. A., Huque, A. K. M. F., Ahasan, M. S. and Song, H. J. 2009. Seroprevalence of specific Brucella infection of cattle in Bangladesh Agricultural University Veterinary Clinics and its surrounding areas. Kor. J. Vet. Serv., 32(3): 219-225.

Rahman, M. S., Han, J. C., Park, J., Lee, J. H., Eo, S. K. and Chae, J. S. 2006. Prevalence of brucellosis and its association with reproductive problems in cows in Bangladesh. Vet. Rec., 159: 180-182.

Rahman, M. S., Huque, M. F., Ahasan, M. S. and Song, H. J. 2010. Indirect enzyme linked immunosorvent assay for the diagnosis of brucellosis in cattle. Kor. J. Vet. Serv., 33(2): 113-119.

Redkar, R., Rose, S., Bricker, B. and DelVecchio, V. 2001. Real-time detection of Brucella abortus, Brucella melitensis and Brucella suis. Mol. Cell. Probes., 15: 43-52.

Reviriego, F. J., Moreno, M. A. and Dominguez, L. 2000. Risk factors for brucellosis seroprevalence of sheep and goat flocks in Spain. Prev. Vet. Med., 44: 167-173.

Sergeant, E. S. 1994. Seroprevalence of Brucella ovis infection in commercial ram flocks in the Tamworth area. N. Z. Vet., J 42: 97-100.

Sharma, R. K., Arun-Kumar, Thapliyal, D. C. and Singh, S. P. 2003. Seroepidemiology of brucellosis in bovines. Indian J. Anim. Sci., 73: 1235-1237.

Uddin, J. M., Rahman, M. S, Hossain, M. A., Akter, S. H., Majumder, S., Park, J. H. and Song H. J. 2007a. Relation between brucellosis and husbandry practices in goats in Bangladesh. Kor. J. Vet. Serv. 30 (2): 259-267.

Uddin, J. M., Rahman, M. S., Akter, S. H., Hossain, M. A., Islam, M. T., Islam, M. A., Park, J. H. and Song, H. J. 2007b. Seroprevalence of brucellosis in small ruminants in selected area of Bangladesh. Kor. J. Vet. Serv. 30(4): 511-525.

Uddin, M. J., Rahman, M. S. and Akter, S. H. 2007c. Brucellosis of goat in Bangladesh. J. Bangladesh Agril. Univ., 5 (2): 287-294.

Waghela, S. 1976. Bulletin of American Health and Production for Africa. 1: 53.

WHO. 1971. Technical Report Series no. 464. Joint FAO/WHO Expert Committee on Brucellosis. $5^{\text {th }}$ Report.

WHO. 1986.Technical Report Series no. 740. Joint FAO/WHO Expert Committee on Brucellosis. $6^{\text {th }}$ Report. 